\title{
Color Temperature Tunable White-Light LED Cluster with Extrahigh Color Rendering Index
}

\author{
Minhao Zhang, ${ }^{1}$ Yu Chen, ${ }^{2}$ and Guoxing $\mathrm{He}^{1}$ \\ ${ }^{1}$ Department of Applied Physics, Dong Hua University, 1882 Yanian Road (W), Shanghai 200051, China \\ ${ }^{2}$ Shanghai Yaming Lighting Co., Ltd., 1001 Jiaxin Road, Jiading District, Shanghai 201801, China \\ Correspondence should be addressed to Guoxing He; gxhe@dhu.edu.cn
}

Received 22 August 2013; Accepted 21 October 2013; Published 23 January 2014

Academic Editors: J.-H. Jou and B. Wei

Copyright (c) 2014 Minhao Zhang et al. This is an open access article distributed under the Creative Commons Attribution License, which permits unrestricted use, distribution, and reproduction in any medium, provided the original work is properly cited.

\begin{abstract}
The correlated color temperature (CCT) tunable white-light LED cluster with extrahigh color rendering property has been found by simulation and fabricated, which consists of three WW LEDs (CCT $=3183 \mathrm{~K})$, one red LED $(634.1 \mathrm{~nm})$, one green LED $(513.9 \mathrm{~nm})$, and one blue LED $(456.2 \mathrm{~nm})$. The experimental results show that this cluster can realize the CCT tunable white-lights with a color rendering index (CRI) above 93, special CRI R9 for strong red above 90, average value of the special CRIs of R9 to R12 for the four saturated colors (red, yellow, green, and blue) above 83, and luminous efficacies above $70 \mathrm{~lm} / \mathrm{W}$ at CCTs of $2719 \mathrm{~K}$ to $6497 \mathrm{~K}$.
\end{abstract}

\section{Introduction}

Semiconductor white light-emitting diodes (LEDs) have attracted a great deal of attention in solid-state lighting applications. Due to their potential for substantial energy savings, high efficiency, small size, and long lifetime, it has been projected that LEDs will broadly replace conventional incandescent and fluorescent lamps for general lighting in the future. It has been reported that a new class of light-detecting retinal cells, the ganglion cells, send their signals to the brain's circadian clock $[1,2]$. Inappropriate lighting conditions were shown in mammals to upset the body chemistry and to lead to deleterious health effects, including cancer [3]. Thus, circadian light sources with tunable color temperature would be beneficial to human health, well-being, and productivity. Furthermore, such circadian lights could lead to a reduced dependence on sleep-inducing pharmaceuticals. For this reason, sources replicating the sun's high color temperature during the midday period and low color temperatures during early morning and at night would be a wonderful illumination source, given that we humans adapted to such a circadian source during evolution. Some correlated color temperature (CCT) tunable white-light LED clusters have been discussed [4-15]. The challenge in the design of white light LED clusters with CCT tunable consists of achieving excellent color rendering index (CRI) values [16] over a reasonable range of color temperatures while at the same time maximizing their luminous efficacies (LEs). One problem with the CRI is that it can give fairly high scores to sources that render some saturated object colors very poorly [17, 18]. In particular, the report from CIE Technical Committee TC 1-62 "Color rendering of white LED light sources" [19] summarizes several problems of the CRI when applied to white LED sources. The CRI score does not correlate well with visual evaluation in many cases. One of reasons was assumed to be the different order of magnitude of the color differences occurring if the reflecting samples are illuminated by a white LED light source and by other light sources, due to the peculiar spectral power distributions of the white LED light sources "interacting" with the spectral reflectance of the test-color samples. This is especially noticeable for the case of test-color sample no. 9 of the CIE method, which is a strong red test-color sample. An improved indicator, color quality scale (CQS), has recently been proposed by National Institute of Standards and Technology [20]. It was found that the CQS provides scores consistent with the CRI for the most recent 
TABLE 1: Average Chi-square per degree of freedom $\left(\mathrm{Chi}^{2} / \mathrm{DoF}\right)$ for the model and real SPDs of these LEDs at different drive currents.

\begin{tabular}{lcccccc}
\hline LED & Red & Amber & Green & Blue & Warm-white & Cool-white \\
\hline Average $\mathrm{Chi}^{2} / \mathrm{DoF} \times 10^{-5}$ & 1.7 & 1.3 & 4.5 & 1.3 & 1.2 & 2.0 \\
\hline
\end{tabular}
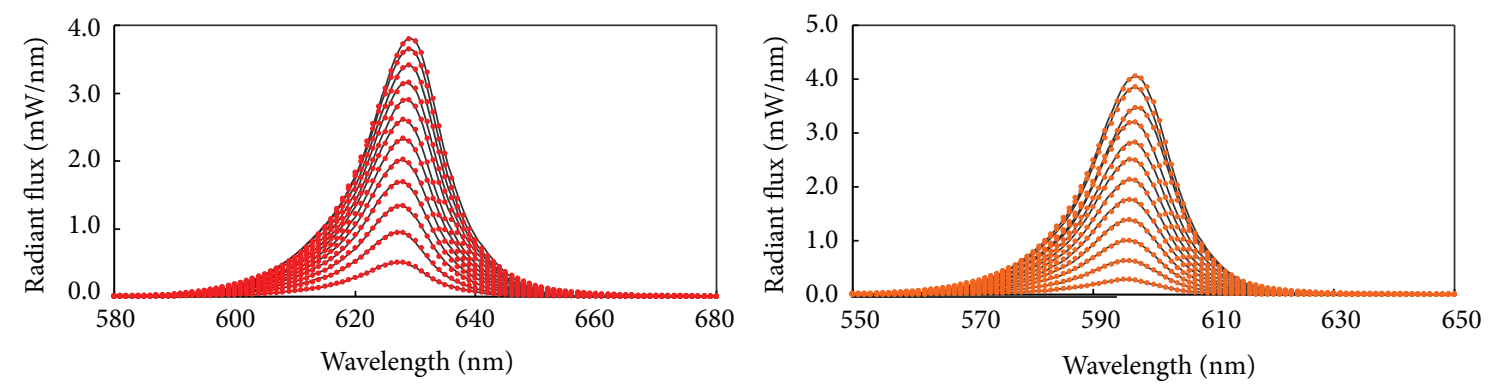

-.. Real red LED

- Model red LED

. $30 \mathrm{~mA}-30 \mathrm{~mA} \cdot 210 \mathrm{~mA}-210 \mathrm{~mA}$

$.60 \mathrm{~mA}-60 \mathrm{~mA} \cdot 240 \mathrm{~mA}-240 \mathrm{~mA}$

$.90 \mathrm{~mA}-90 \mathrm{~mA} \cdot 270 \mathrm{~mA}-270 \mathrm{~mA}$

. $120 \mathrm{~mA}-120 \mathrm{~mA} \cdot 300 \mathrm{~mA}-300 \mathrm{~mA}$

$\cdot 150 \mathrm{~mA}-150 \mathrm{~mA} \cdot 330 \mathrm{~mA}-330 \mathrm{~mA}$

. $180 \mathrm{~mA}-180 \mathrm{~mA} \cdot 350 \mathrm{~mA}-350 \mathrm{~mA}$
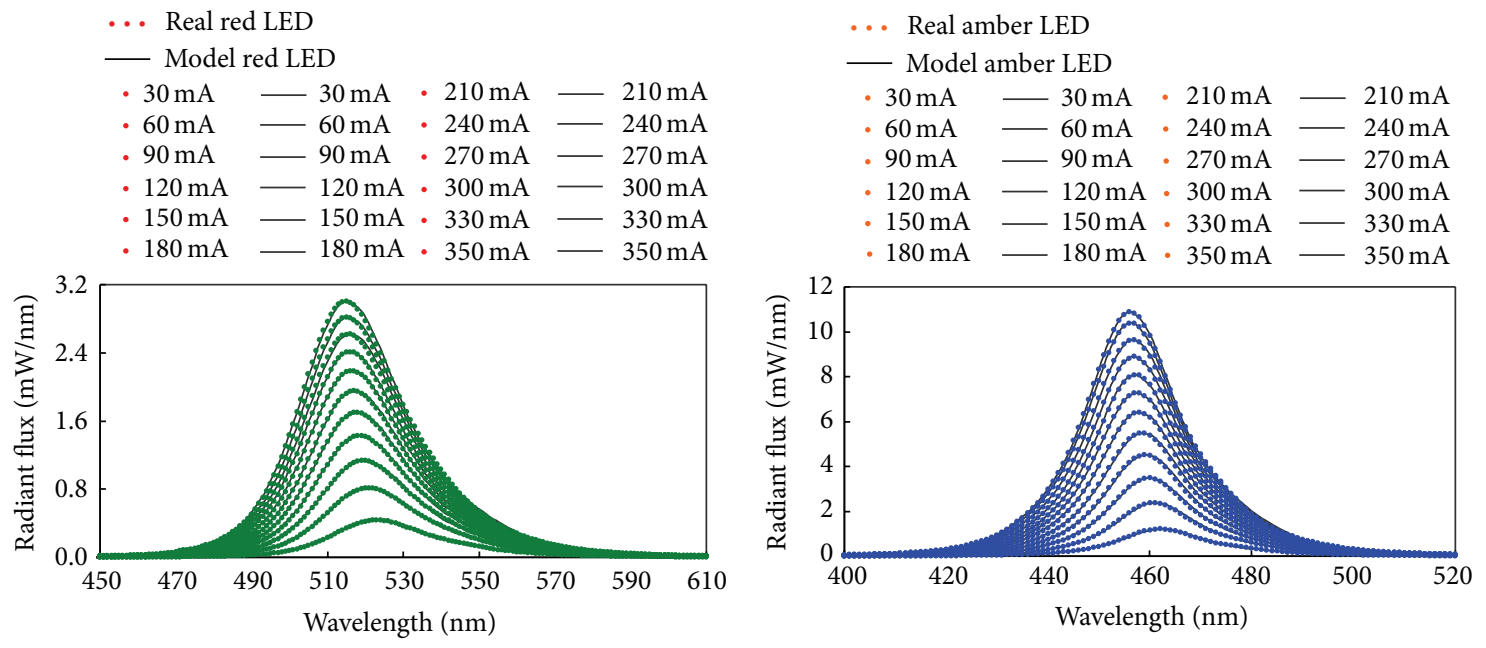

... Real green LED

- Model green LED

. $30 \mathrm{~mA}-30 \mathrm{~mA} \cdot 210 \mathrm{~mA}-210 \mathrm{~mA}$

$.60 \mathrm{~mA}-60 \mathrm{~mA} \cdot 240 \mathrm{~mA}-240 \mathrm{~mA}$

. $90 \mathrm{~mA}-90 \mathrm{~mA} \cdot 270 \mathrm{~mA}-270 \mathrm{~mA}$

$\cdot 120 \mathrm{~mA}-120 \mathrm{~mA} \cdot 300 \mathrm{~mA}-300 \mathrm{~mA}$

- $150 \mathrm{~mA}-150 \mathrm{~mA} \cdot 330 \mathrm{~mA}-330 \mathrm{~mA}$

$.180 \mathrm{~mA}-180 \mathrm{~mA}$
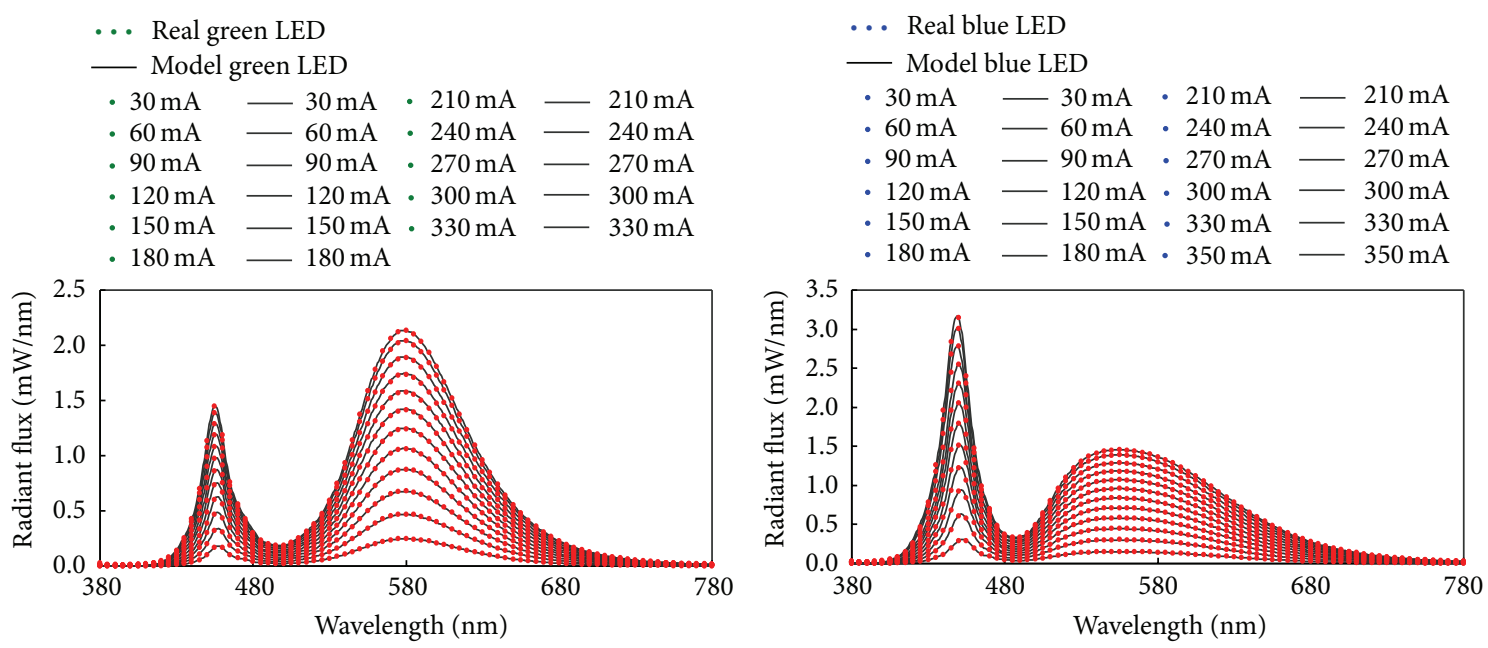

... Real warm-white LED

- Model warm-white LED

$.30 \mathrm{~mA}-30 \mathrm{~mA} \cdot 210 \mathrm{~mA}-210 \mathrm{~mA}$
$.60 \mathrm{~mA}-60 \mathrm{~mA} \cdot 240 \mathrm{~mA}-240 \mathrm{~mA}$
$.90 \mathrm{~mA}-90 \mathrm{~mA} \cdot 270 \mathrm{~mA}-270 \mathrm{~mA}$
$.120 \mathrm{~mA}-120 \mathrm{~mA} \cdot 300 \mathrm{~mA}-300 \mathrm{~mA}$
$.150 \mathrm{~mA}-150 \mathrm{~mA} \cdot 330 \mathrm{~mA}-330 \mathrm{~mA}$
$.180 \mathrm{~mA}-180 \mathrm{~mA}$

.. Real cool-white LED
- Model cool-white LED
$.30 \mathrm{~mA}-30 \mathrm{~mA} \cdot 210 \mathrm{~mA}-210 \mathrm{~mA}$
$.60 \mathrm{~mA}-60 \mathrm{~mA}: 240 \mathrm{~mA}-240 \mathrm{~mA}$
$.90 \mathrm{~mA}-90 \mathrm{~mA} \cdot 270 \mathrm{~mA}-270 \mathrm{~mA}$
$.120 \mathrm{~mA}-120 \mathrm{~mA} \cdot 300 \mathrm{~mA}-300 \mathrm{~mA}$
$.150 \mathrm{~mA}-150 \mathrm{~mA} \cdot 330 \mathrm{~mA}-330 \mathrm{~mA}$
$.180 \mathrm{~mA}-180 \mathrm{~mA}$

FIGURE 1: SPDs of model and real LEDs (red, amber, green, blue, warm-white, and cool-white) at different drive currents. 
phosphor type LED products, RGBA LEDs, and traditional discharge lamps [20]. So the CRI as a metric for evaluating the color rendering abilities of white-light sources is suitable for the white LED cluster with the phosphor-conversion LED (PC LED).

In this paper, a CCT tunable white-light LED cluster with extrahigh color rendering (CRI > 93 and R9 > 90) has been found by simulation. The predicted and measured results are presented.

\section{Model for LED Spetra}

A model for LED spectra at different drive currents was developed. The relative SPD of the single color LED, $\mathrm{S}_{\mathrm{LED}}\left(\lambda, \lambda_{0}, \Delta \lambda\right)$, was given by

$$
\begin{aligned}
\mathrm{S}_{\mathrm{LED}}\left(\lambda, \lambda_{0}, \Delta \lambda\right)= & \exp \left[-\frac{k_{1}\left(\lambda-\lambda_{0}\right)^{2}}{(\Delta \lambda)^{2}}\right] \\
& \times \cosh \left[\frac{k_{2}\left(\lambda-\lambda_{0}\right)^{2}}{(\Delta \lambda)^{2}}\right],
\end{aligned}
$$

where

$$
\begin{array}{r}
\Delta \lambda= \begin{cases}\Delta \lambda_{1}, & \left(\lambda<\lambda_{0}\right) \\
\Delta \lambda_{2}, & \left(\lambda \geq \lambda_{0}\right),\end{cases} \\
k_{i}= \begin{cases}k_{i}^{1}, & \left(\lambda<\lambda_{0}\right) \\
k_{i}^{2}, & \left(\lambda \geq \lambda_{0}\right),\end{cases} \\
(i=1,2),
\end{array}
$$

where $\lambda_{0}$ refers to peak wavelength, $\Delta \lambda_{1}$ refers to the left-half-spectral width which is $2 \int_{380 \mathrm{~nm}}^{\lambda_{0}} \mathrm{~S}_{\mathrm{LED}}(\lambda) d \lambda$, and $\Delta \lambda_{2}$ refers to the right-half-spectral width which is $2 \int_{\lambda_{0}}^{780 \mathrm{~nm}} \mathrm{~S}_{\mathrm{LED}}(\lambda) d \lambda . k_{i}(i=1,2)$ are characteristic parameters of spectral shape. The units of peak wavelength and halfspectral width are nanometers.

The relationships of $\lambda_{0}$ and drive current $I_{F}, \Delta \lambda_{i}$, and $I_{F}$ were given by (3), and (4), respectively [10], as follows:

$$
\begin{gathered}
\lambda_{0}\left(I_{F}\right)=A_{\lambda_{0}} \exp \left(B_{\lambda_{0}} I_{F}\right)+C_{\lambda_{0}} \\
\Delta \lambda_{i}\left(I_{F}\right)=A_{\Delta \lambda i}+B_{\Delta \lambda i} I_{F}
\end{gathered}
$$

where $A_{\lambda_{0}}, B_{\lambda_{0}}$, and $C_{\lambda_{0}}$ are function parameters of $\lambda_{0}\left(I_{F}\right)$; $A_{\Delta \lambda i}$ and $B_{\Delta \lambda i}$ are function parameters of $\Delta_{\lambda i}\left(I_{F}\right)$. The unit of drive current is milliamperes.

The relative SPD of phosphor-coated white LED, $S_{W}(\lambda)$, was given by [10]

$$
S_{W}(\lambda)=S_{B}(\lambda)+S_{F}(\lambda),
$$

where $S_{W}(\lambda), S_{B}(\lambda)$, and $S_{F}(\lambda)$ are the white spectra, blue spectra, and the fluorescence spectra of the white LED, respectively. $S_{B}(\lambda)$ can be expressed by $(1) . S_{F}(\lambda)$ can be determined by $\sum_{380 \mathrm{~nm}}^{475 \mathrm{~nm}}\left[S_{W}(\lambda)-S_{B}(\lambda)\right]^{2} \rightarrow \min$. Equations (3) and (4) can be applied to blue spectra $S_{B}(\lambda)$.

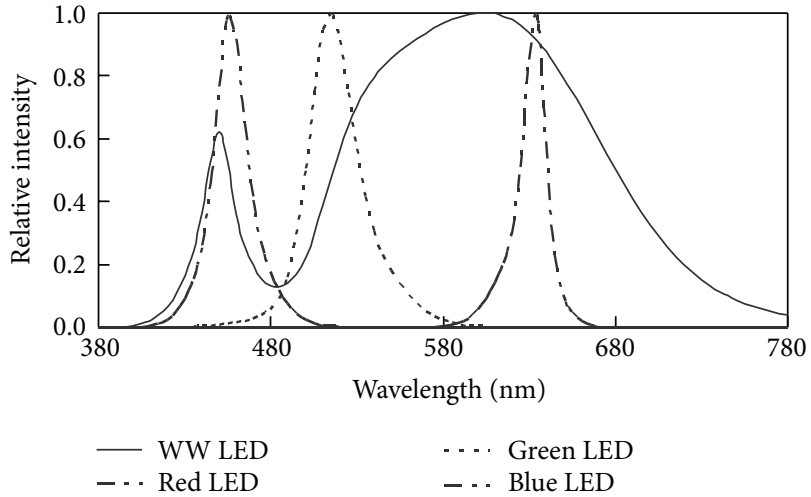

FIGURE 2: Relative SPDs of WW, red, green, and blue LEDs at drive current of $350 \mathrm{~mA}$.

The relationship of the fluorescent spectra and the drive current, $S_{F}\left(\lambda, I_{F}\right)$, was given by [10]

$$
S_{F}\left(\lambda, I_{F}\right)=S_{F}\left(\lambda, I_{F \max }\right)+A_{F} \exp \left(B_{F} I_{F}\right),
$$

where $A_{F}$ and $B_{F}$ are function parameters of $S_{F}\left(\lambda, I_{F}\right)$. To predict the drive current and input power $P_{\text {in }}$ of LED at given luminous flux $\Phi$, the relationships of $I_{F}$ and $\Phi, P_{\text {in }}$, and $\Phi$ were given by (7) and (8), respectively, as follows:

$$
\begin{gathered}
I_{F}(\Phi)=k_{I} \Phi^{\gamma}\left(1+c_{I} \Phi^{2}\right) \\
P_{\text {in }}(\Phi)=k_{P} \Phi^{\gamma}\left(1+c_{P} \Phi^{2}\right),
\end{gathered}
$$

where $k_{I}, c_{I}$, and $\gamma$ are function parameters of $I_{F}(\Phi) ; k_{P}$, $c_{P}$, and $\gamma^{\prime}$ are function parameters of $P_{\text {in }}(\Phi)$. The units of luminous flux and input power are lumens and watts, respectively.

The SPDs of model and real LEDs (red, amber, green, blue, warm-white, and cool-white) at different drive currents are shown in Figure 1. The average Chi-square per degree of freedom $\left(\mathrm{Chi}^{2} / \mathrm{DoF}\right)$ for the model and real SPDs of these LEDs at different drive currents is shown in Table 1. The results show that the SPDs of model LEDs are very close to those of real LEDs at different drive currents.

\section{Simulation and Realization CCT Tunable White-Light Cluster}

To analyze the possible performance of the CCT tunable white-light LED cluster, the simulation program has been developed according to the principle of additive color mixture [10]. The simulation program can predict not only the relative SPD, chromaticity coordinates, but also numbers of LED $(N)$, drive currents $\left(I_{F}\right)$, the input power $\left(P_{\text {in }}\right)$, the luminous flux $(\Phi)$, and the luminous efficacy $(\eta)$ according to requirements of CRI, R9, CCT, and the distance from the Planckian locus on the CIE 1960 uv chromaticity diagram (dC), with polarity, plus (above the Planckian locus) or minus (below the Planckian locus) [15].

The CCT tunable white-light LED cluster with extrahigh color rendering has been found by simulation analysis, 


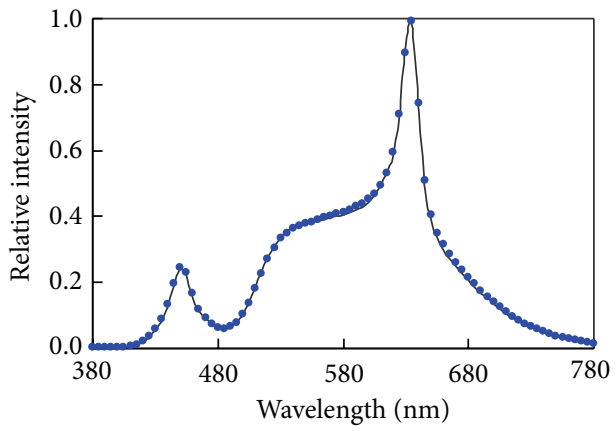

(a)

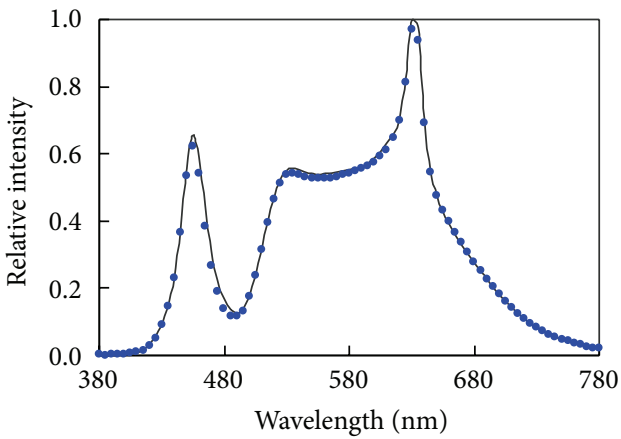

(c)

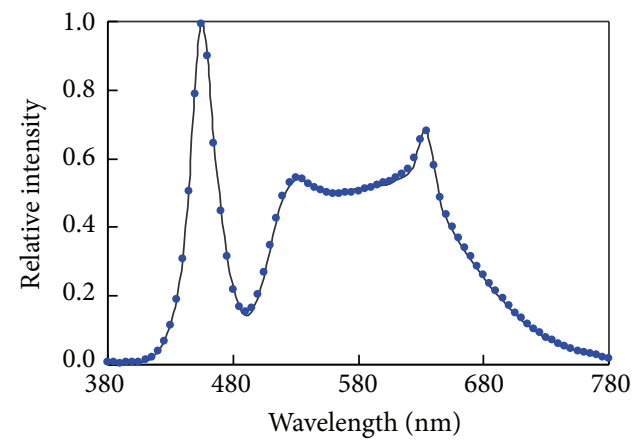

(e)

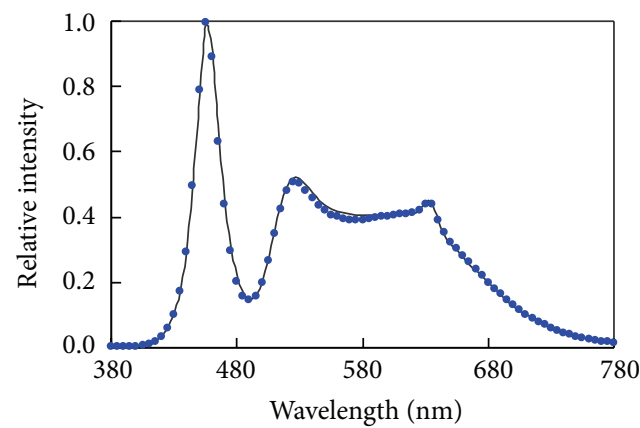

- Measured

- Predicted

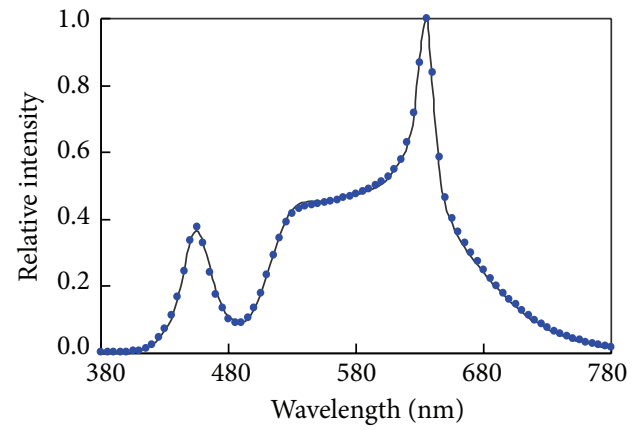

(b)

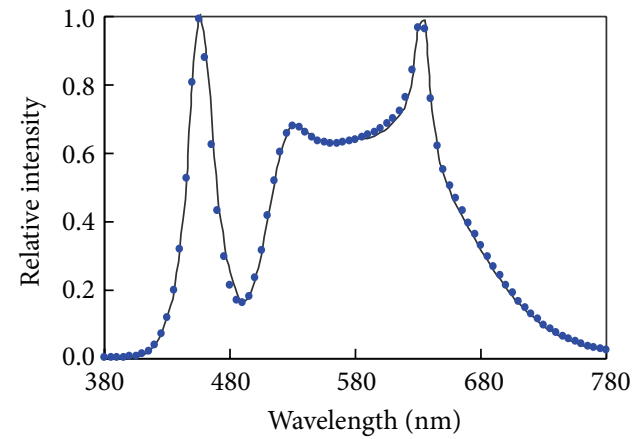

(d)

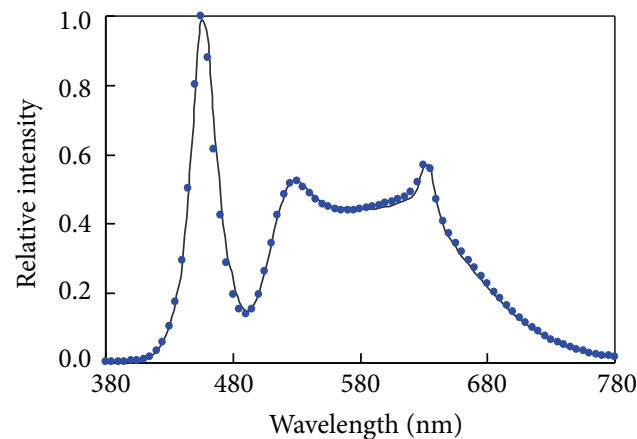

(f)

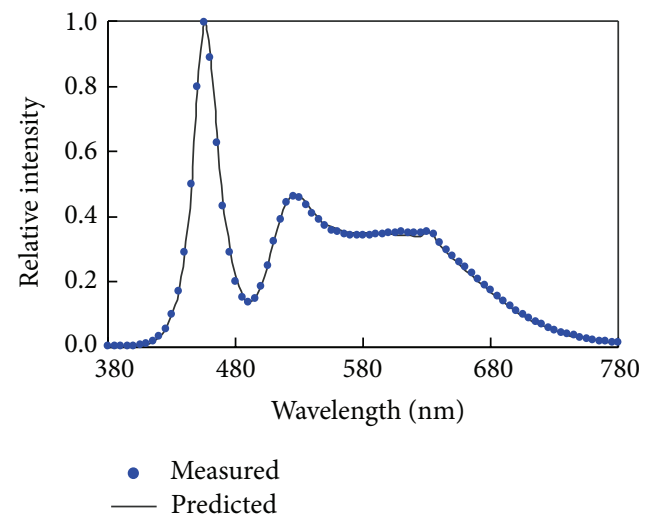

(h)

Figure 3: Predicted and measured SPDs of the white light-LED cluster at different CCTs: (a) CCT = $2719 \mathrm{~K}$; (b) CCT = 3028 K; (c) CCT = $3458 \mathrm{~K}$; (d) CCT = $3983 \mathrm{~K}$; (e) CCT = $4537 \mathrm{~K}$; (f) CCT = $5012 \mathrm{~K}$; (g) CCT = $5723 \mathrm{~K}$; (h) CCT = $6497 \mathrm{~K}$. 
TABLE 2: The predicted and measured results of the white-light LED cluster at $T_{a}=45^{\circ} \mathrm{C}$.

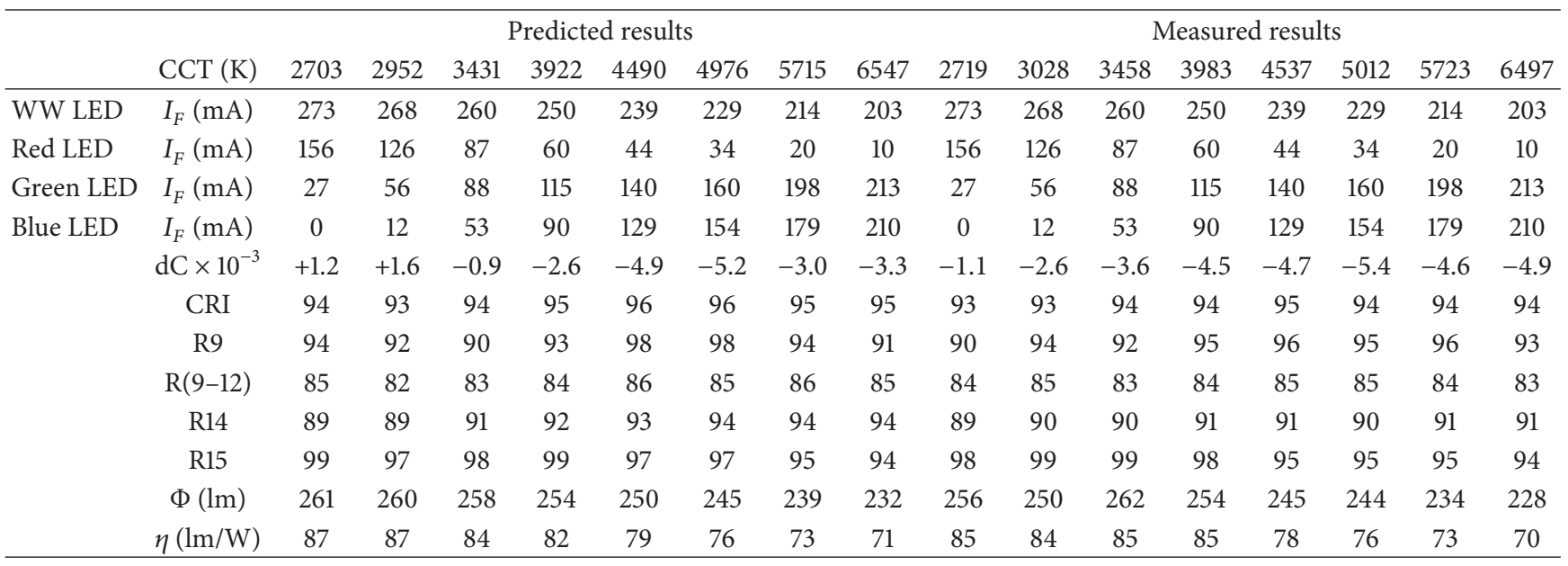

which consists of three warm-white (WW) LEDs (excited wavelength $\lambda_{0}=450.5 \mathrm{~nm}$, CCT $=3183 \mathrm{~K}, \Phi=93.2 \mathrm{~lm}$, $P_{\text {in }}=1.15 \mathrm{~W}$, and $\eta=81.0 \mathrm{~lm} / \mathrm{W}$ at $I_{F}=350 \mathrm{~mA}$ ), one red LED $\left(\lambda_{0}=634.1 \mathrm{~nm}, \Phi=51.6 \mathrm{~lm}\right.$, and $P_{\text {in }}=0.83 \mathrm{~W}$ at $\left.I_{F}=350 \mathrm{~mA}\right)$, one green $\operatorname{LED}\left(\lambda_{0}=513.9 \mathrm{~nm}, \Phi=61.5 \mathrm{~lm}\right.$, and $P_{\text {in }}=1.24 \mathrm{~W}$ at $\left.I_{F}=350 \mathrm{~mA}\right)$, and one blue $\operatorname{LED}\left(\lambda_{0}=456.2 \mathrm{~nm}, \Phi=15.3 \mathrm{~lm}\right.$, and $P_{\text {in }}=1.18 \mathrm{~W}$ at $I_{F}=350 \mathrm{~mA}$ ). The SPDs, the luminous flux, and the input power of the WW LED, red, green, and blue LEDs at drive currents of 30 350 mA are measured by an automated photometric/radiometric measurement setup and a power meter at an ambient temperature $(\mathrm{Ta})$ of $25^{\circ} \mathrm{C}$. The relative SPDs of WW, red, green, and blue LEDs at drive current of $350 \mathrm{~mA}$ are shown in Figure 2. An opal bulb is used to mix the light from the single color LEDs to generate uniform white light. The drive circuit is stable and can be precisely controlled, so that it can drive the LED cluster stably and properly according to the optimal drive currents. The predicted and measured SPDs of the white-light LED cluster at different CCTs are shown in Figure 3. The results show that the SPDs of predicted LEDs are very close to those of measured LEDs at different drive currents. The predicted and measured color rendering property and the luminous efficacy of this cluster at an ambient temperature $\left(T_{a}\right)$ of $45^{\circ} \mathrm{C}$ are shown in Table 2 . The $\mathrm{R}(9-12)$ in Table 2 is the average value of the special color rendering indices $\mathrm{R} 9$ to R12 of the four saturated colors (red, yellow, green, and blue). Table 2 indicates that the predicted results are very close to the measured values. The experimental results show that this cluster can realize CCT tunable white-light with a CRI above 93, $\mathrm{R} 9$ above $90, \mathrm{R}(9-12)$ above 83 , and a luminous efficacy above $70 \mathrm{~lm} / \mathrm{W}$ at CCTs of $2719 \mathrm{~K}$ to $6497 \mathrm{~K}$. Furthermore, their special CRIs of R14 and R15 corresponding to the colors of the skin on the face of European and Chinese women are also very high (R14 > 89 and R15 > 94). R14 and R15 are especially important for interior lighting.

\section{Conclusion}

The white-light LED cluster consisting of the WW $(\mathrm{CCT}=3183 \mathrm{~K})$, red $(634.1 \mathrm{~nm})$, green $(513.9 \mathrm{~nm})$, and blue $(456.2 \mathrm{~nm})$ LEDs can realize the CCT tunable whitelight with a CRI above 93, R9 above 90, R(9-12) above 83, and a luminous efficacies above $70 \mathrm{~lm} / \mathrm{W}$ at CCTs of $2719 \mathrm{~K}$ to $6497 \mathrm{~K}$.

\section{Conflict of Interests}

The authors declare that there is no conflict of interests regarding the publication of this paper.

\section{Acknowledgment}

The authors gratefully acknowledge support by Shanghai Science and Technology Committee (no. 13111104200).

\section{References}

[1] S. Hattar, H.-W. Liao, M. Takao, D. M. Berson, and K.-W. Yau, "Melanopsin-containing retinal ganglion cells: architecture, projections, and intrinsic photosensitivity," Science, vol. 295, no. 5557, pp. 1065-1070, 2002.

[2] D. M. Berson, F. A. Dunn, and M. Takao, "Phototransduction by retinal ganglion cells that set the circadian clock," Science, vol. 295, no. 5557, pp. 1070-1073, 2002.

[3] D. E. Blask, R. T. Dauchy, L. A. Sauer, J. A. Krause, and G. C. Brainard, "Growth and fatty acid metabolism of human breast cancer (MCF-7) xenografts in nude rats: impact of constant light-induced nocturnal melatonin suppression," Breast Cancer Research and Treatment, vol. 79, no. 3, pp. 313-320, 2003.

[4] I. Speier and M. Salsbury, "Color temperature tunable white light LED system," in Sixth International Conference on Solid State Lighting, vol. 6337 of Proceedings of SPIE, August 2006.

[5] C. Hoelen, J. Ansems, P. Deurenberg et al., "Color tunable LED spot lighting," in Sixth International Conference on Solid State Lighting, vol. 6337 of Proceedings of SPIE, San Diego, Calif, USA, August 2006.

[6] M. Funato, K. Hayashi, M. Ueda, Y. Kawakami, Y. Narukawa, and T. Mukai, "Emission color tunable light-emitting diodes composed of InGaN multifacet quantum wells," Applied Physics Letters, vol. 93, no. 2, Article ID 021126, 2008. 
[7] J.-H. Jou, C.-J. Wang, Y.-P. Lin et al., “Color-stable, efficient fluorescent pure-white organic light-emitting diodes with device architecture preventing excessive exciton formation on guest," Applied Physics Letters, vol. 92, no. 22, Article ID 223504, 2008.

[8] J.-H. Jou, M.-H. Wu, S.-M. Shen et al., "Sunlight-style colortemperature tunable organic light-emitting diode," Applied Physics Letters, vol. 95, no. 1, Article ID 013307, 2009.

[9] J.-C. Su and C.-L. Lu, "Color temperature tunable white light emitting diodes packaged with an omni-directional reflector," Optics Express, vol. 17, no. 24, pp. 21408-21413, 2009.

[10] G. He and L. Zheng, "Color temperature tunable white-light light-emitting diode clusters with high color rendering index," Applied Optics, vol. 49, no. 24, pp. 4670-4676, 2010.

[11] G. He and L. Zheng, "White-light LED clusters with high color rendering," Optics Letters, vol. 35, no. 17, pp. 2955-2957, 2010.

[12] M.-C. Chien and C.-H. Tien, "Cluster LEDs mixing optimization by lens design techniques," Optics Express, vol. 19, no. 14, pp. A804-A817, 2011.

[13] M.-C. Chien and C.-H. Tien, "Multispectral mixing scheme for LED clusters with extended operational temperature window," Optics Express, vol. 20, no. 6, pp. A245-A254, 2012.

[14] P. Zhong, G. X. He, and M. H. Zhang, "Spectral optimization of the color temperature tunable white light-emitting diode (LED) cluster consisting of direct-emission blue and red LEDs and a diphosphor conversion LED," Optics Express, vol. 20, no. S5, pp. A684-A693, 2012.

[15] J. N. Yu, H. Lin, F. F. Wang et al., "Sunlight-like, colortemperature tunable white organic light-emitting diode with high color rendering index for solid-state lighting application," Journal of Materials Chemistry, vol. 22, no. 41, pp. 22097-22101, 2012.

[16] International Commission on Illumination, Method of Measuring and Specifying Colour Rendering Properties of Light Sources, CIE Central Bureau, Vienna, Austria, 1995.

[17] N. Narendran and L. Deng, "Color rendering properties of LED light sources," in Solid State Lighting II, vol. 4776 of Proceedings of SPIE, pp. 61-67, Seattle, Wash, USA, July 2002.

[18] N. Sándor and J. Schanda, "Visual colour rendering based on colour difference evaluations," Lighting Research and Technology, vol. 38, no. 3, pp. 225-239, 2006.

[19] CIE, TC 1-62: Color Rendering of White LED Light Sources, CIE, Vienna, Austria, 2007.

[20] W. Davis and Y. Ohno, "Color quality scale," Optical Engineering, vol. 49, no. 3, Article ID 033602, 2010. 

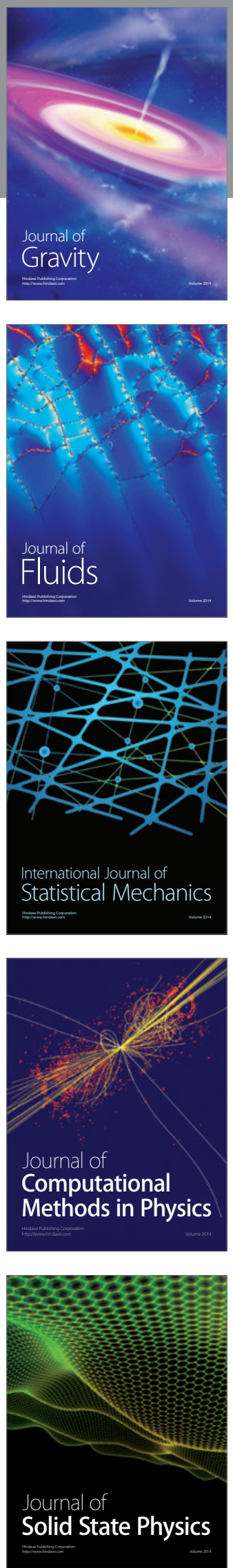

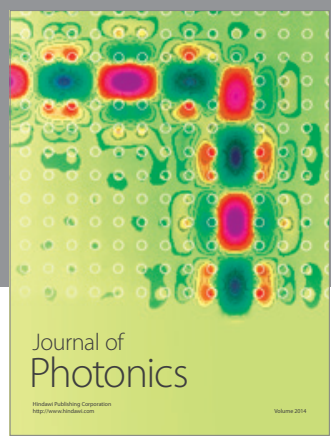

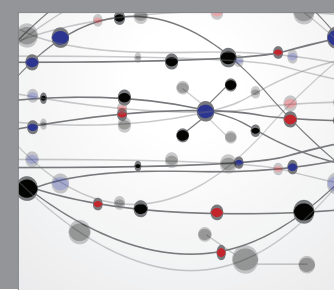

The Scientific World Journal

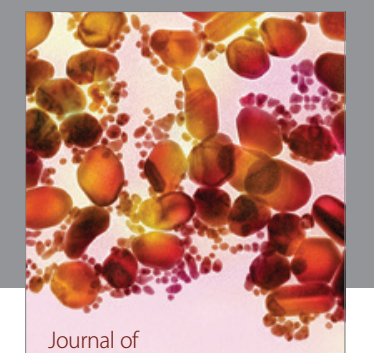

Soft Matter
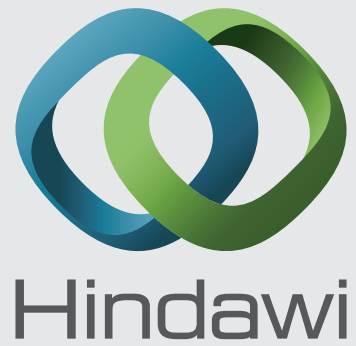

Submit your manuscripts at

http://www.hindawi.com
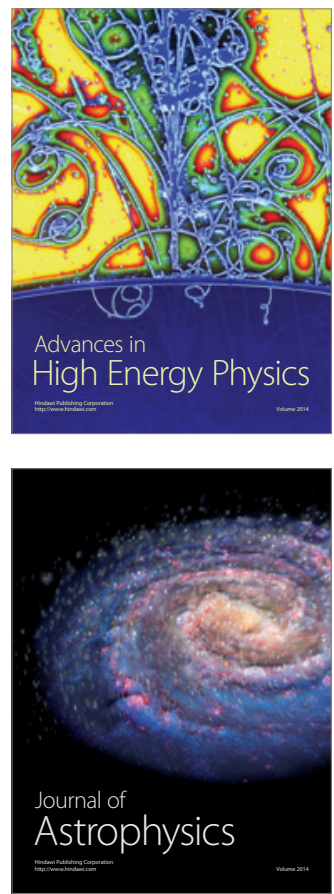
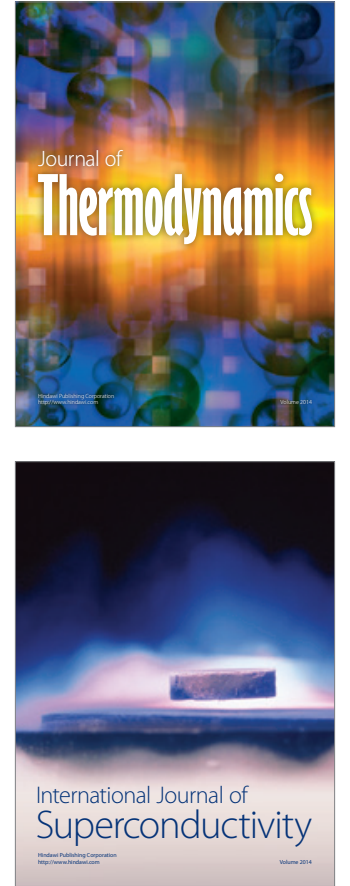
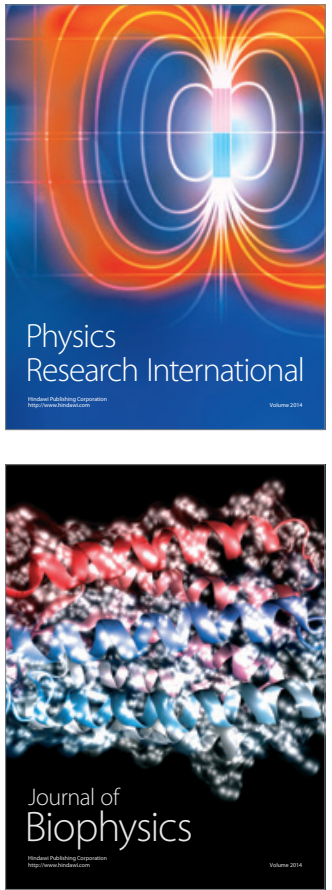
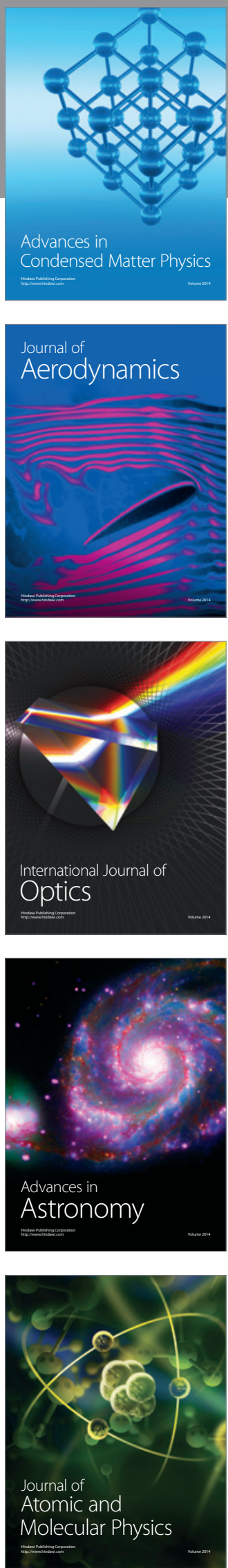